\title{
Galvanic skin reactions associated with nonpresentation of an accustomed valued object in humans'
}

\author{
MONROE WEIL ${ }^{2}$ and EDWARD S. \\ KATKIN, State University of New York at \\ Buffalo, Buffalo, N.Y. 14214
}

This study investigated Amsel's theory of frustrative nonreward using a psychophysiological measure, the galvanic skin response (GSR), instead of an instrumental measure. Following a series of presentations of a valued object, it was found that nonpresentation produced an increase in the GSR, analogous to the frustration effect for instrumental measures. It was also found that presentation cues during nonpresentation were important for the elicitation of frustration.

Amsel (1958) has applied the term frustrative nonreward to a situation in which an organism ceases to receive a reward for the performance of a previously rewarded task. According to Amsel, frustrative nonreward results in frustration, an hypothetical motivational state which contributes to the drive level of the organism. The drive effects of frustration can be measured as an increase in the vigor of instrumental behavior immediately following the frustrative event. This increase in vigor is known as the frustration effect (FE).

An experiment by Amsel \& Hancock (1957) demonstrated that nonreward elicits frustration to the degree that rewarded trials result in the classical conditioning of fractional anticipatory goal responses $\left(\mathrm{r}_{\mathrm{g}} \mathrm{s}\right)$ to cues in the instrumental response sequence. The role of cues in frustration was also investigated by Longstreth (1966). He reasoned that if nonreward is introduced after a series of rewards, then the more closely the nonreward situation resembles the reward situation, the greater the frustration should be because of the stronger elicitation of $r_{g} s$. In accord with his hypothesis, he obtained the FE when the cues during nonreward were similar to those of reward, but not when the cues were less similar.

Although the FE has been demonstrated in numerous studies of frustrative nonreward, Brown \& Farber (1951) have suggested the possibility that, in frustration experiments, the increased vigor which follows the frustrative event might be the result of prior learning rather than increased drive. According to this hypothesis, Ss may have learned from previous situations that the most likely method of obtaining a temporarily blocked goal object is to increase the vigor of their responses. This learning can then be transferred to new situations through the mediation of internal, frustration-produced cues.

An alternative, and possibly more direct, method of evaluating the drive effects of frustration which would not be susceptible to the learning interpretation of the instrumental measures would appear to involve the use of psychophysiological measures, such as the galvanic skin response (GSR). In the present study, the GSR was used to investigate frustrative nonreward in humans. The task used to induce frustration was similar to instrumental conditioning in that $S$ had to perform a response to receive a valued object, but differed from it in that $S$ did not have to learn the response. He was instructed to press a switch each time a tone terminated in order to obtain a marble from a marble dispenser. This task required only a slight movement of the thumb of the free hand so that GSR artifacts were minimal. For half of the Ss the marbles had monetary value, and for the other half they did not. It was predicted that nonpresentation of the valued objects after a series of presentations would produce an increase in the magnitude of the GSR, analogous to the FE for instrumental measures. An increase in the GSR with nonpresentation might have occurred because the change in stimulus conditions produced an orienting response (OR); thus, in order to demonstrate frustration, any increase for Ss receiving money would have had to be greater than that due solely to the OR. Therefore, Ss for whom the marbles had no value served as controls for the OR.

This study also investigated, as did Longstreth's, the effect on frustration of the similarity of stimulus conditions between presentation and nonpresentation of the valued object. Thus, designating the tone as $S 1$, the sound produced by the operation of the marble dispenser as $S 2$, and the valued

object as S3, when S3 was no longe presented, some Ss continued to receive $S 1$ and $S 2$, while others received just $S 1$. It was predicted that nonpresentation accompanied by $S 2$ would produce a greater increase in the GSR than nonpresentation without S2.

\section{SUBJECTS}

The Ss were 20 male students from introductory psychology classes at the State University of New York at Buffalo who received credit toward fulfilling a course requirement.

\section{APPARATUS}

The experimental chamber was a ventilated, soundproof room, illuminated by three shielded $60-\mathrm{W}$ incandescent bulbs. It contained a comfortable reclining chair, apparatus to be manipulated by Ss, and various pieces of equipment necessary for the attachment of GSR electrodes. The apparatus for amplifying and recording the GSRs was located outside the chamber. An intercom system allowed $\mathrm{E}$ to hear any unusual movement or activity which might have created artifactual skin resistance changes.

Two Ag-AgCl GSR electrodes were used, with one placed on the thenar eminence of the palm of the left hand and the other on the left forearm. Beckman Offner $\mathrm{NaCl}$ paste was used to establish contact between the electrodes and the skin. Basal skin resistance was amplified by a GSR amplifier, Biophysical Research Instruments, Inc., Model 201, which generated a dc current of 20 microA, and recorded on a Grass Polygraph, Model 5D, operating at a paper speed of $5 \mathrm{~mm} / \mathrm{sec}$. The Ss wore Lafayette stereo headphones, Model F.767, through which $45-\mathrm{dB}$ SPL $1000-\mathrm{Hz}$ tones, of $2-\mathrm{sec}$ duration were presented to the ears. The tones were produced by a Hewlett-Packard audio oscillator, Model $200 \mathrm{ABR}$, and their duration was controlled by a Hunter decade interval timer, Model $111-\mathrm{C}$, with the intertrial intervals regulated by a Gerbrands $2 \mathrm{~mm} / \mathrm{sec}$ interval programmer, Model $1 \mathrm{~A}$.

In front of Ss' chair was a gray wooden stand, on top of which was a gray marble-dispensing device. At the bottom of the marble dispenser, resting on the stand, was a Plexiglas container, in which the marbles were collected. The container was at eye level, about $5 \mathrm{ft}$ from the reclining $\mathrm{Ss}$, permitting a clear view of the marbles. The

Table 1

Means and SDs of Presentation GSRs for Money and No Money Conditions at each Trial Block

\begin{tabular}{llcccccccccc} 
& & \multicolumn{10}{c}{ Trial Blocks } \\
\cline { 3 - 10 } Group & & 1 & 2 & 3 & 4 & 5 & 6 & 7 & 8 & 9 & 10 \\
\hline \multirow{3}{*}{ Money } & M & .037 & .024 & .023 & .030 & .024 & .029 & .021 & .012 & .015 & .014 \\
& SD & .025 & .021 & .022 & .034 & .020 & .024 & .023 & .013 & .013 & .011 \\
\multirow{3}{*}{ No Money } & M & .024 & .012 & .019 & .024 & .021 & .020 & .025 & .023 & .032 & .041 \\
& SD & .022 & .013 & .016 & .019 & .020 & .017 & .022 & .016 & .034 & .028 \\
\hline
\end{tabular}


Table 2

Means and SDs of GSRs for Money and No Money Conditions with and without Dispenser Sound at Trial Block 10 of Presentation and Trial Block 1 of Nonpresentation

\begin{tabular}{lccccc}
\hline & \multicolumn{4}{c}{ Trial Blocks } \\
\cline { 2 - 4 } & \multicolumn{2}{c}{10} & & \multicolumn{2}{c}{1} \\
\cline { 2 - 3 } \cline { 5 - 6 } Group & $M$ & SD & & $M$ & SD \\
\hline M-DS & .008 & .008 & & .060 & .053 \\
M-NDS & .020 & .010 & .040 & .027 \\
NM-DS & .037 & .029 & .019 & .022 \\
NM-NDS & .045 & .030 & .038 & .023 \\
\hline
\end{tabular}

dispenser was activated by a toggle switch which could be pressed in only one direction, and, when released, automatically returned to the off position. The marble dropped into the container $0.5 \mathrm{sec}$ after the switch was pressed. The switch was mounted in the center of an aluminum chassis, which, in turn, was mounted on a gray wooden board.

\section{PROCEDURE}

The Ss were assigned to one of four experimental conditions: money-dispenser sound (M-DS), money-no dispenser sound (M-NDS), no money-dispenser sound (NM-DS), and no money-no dispenser sound (NM-NDS). After Ss were brought into the chamber they were seated in the reclining chair, the electrodes were attached and the headphones were put on, and the switchboard was placed on their laps. The $\mathrm{E}$ then left the chamber, and Ss were given a 5 -min rest period, followed by 10 habituation trials to the tone.

After the habituation trials, E entered the chamber and gave Ss instructions concerning presentation of the marbles. The Ss were instructed to press the switch once with the thumb of the right hand immediately following each presentation of the tone. In addition, $\mathrm{Ss}$ in the money groups were told that they would receive 10 cents at the end of the experiment for each marble they obtained, and a container filled with 80 dimes was placed alongside the empty one for the marbles. The $E$ then left the chamber and presented the tone for 30 trials at the following randomly varied intertrial intervals: $45,50,55,60,65,70$, and 75 sec. The Ss received a marble by pressing the switch on each of Trials 1-20. On Trials 21-30, however, pressing the switch no longer produced a marble; for $S s$ in the dispenser sound groups, the switch continued to operate, producing the sound associated with the dispenser, but for Ss in the no dispenser sound groups, the switch no longer activated the dispenser, so that this sound did not occur.
At the end of the 30 trials, E entered the chamber and removed the switchboard, headphones, and electrodes from Ss. If they were in the money groups, they were informed that there were 20 marbles in the container, and received $\$ 2.00$. The dimes in the container were not used for payment, so that their number remained constant.

\section{RESULTS}

The magnitude of the GSR, expressed as change in $\log$ conductance, was used as the response measure. An increase in skin conductance was considered a response if it occurred between 0.5 and $5.5 \mathrm{sec}$ after the switch was pressed. The time between the initiation and the peak of a response was limited to $10.5 \mathrm{sec}$ after switch-pressing. The GSRs were averaged into trial blocks of two trials each.

The presentation data for the money and no money groups (the dispenser sound variable was in effect during nonpresentation only) are shown in Table 1 . Toward the end of presentation, the no money group increased while the money group declined.

These data were analyzed by a 2 by 10 repeated measures analysis of variance, which indicated a significant Money by Trial Blocks interaction $(F=2.98, \mathrm{df}=9 / 162$, $\mathrm{p}<.005$ ), but no other significant effects This interaction confirms the observation that the money group differed from the no money group. A trend analysis of the interaction revealed a significant difference between the linear components of the two groups $(\mathrm{F}=22.47, \mathrm{df}=1 / 162, \mathrm{p}<.001)$.

The data for Trial Block 10 of presentation, the last presentation trial block, and Trial Block 1 of nonpresentation, the first nonpresentation trial block, are shown in Table 2. There was an increase for the money groups from Trial Block 10 to Trial Block 1, with the increase for Group M-DS greater than that for Group M-NDS. Over the two trial blocks, the no money groups declined.

These data were analyzed by a 2 by 2 by 2 repeated measures analysis of variance, which indicated a significant Money by Trial Blocks interaction $(F=13.10, \mathrm{df}=1 / 16, \mathrm{p}<.005)$, but no other significant effects. This interaction confirms the observation that the money groups differed from the no money groups.

Since it was predicted that nonpresentation accompanied by the dispenser sound would produce a greater increase than nonpresentation without the dispenser sound, $F$ tests for the simple main effects of the trial blocks factor (Winer,
1962) were computed in order to determine whether both Group M-DS and Group M-NDS increased significantly from the end of presentation to the beginning of nonpresentation. These indicated that for Group M-DS the increase was significant $(F=14.93, \mathrm{df}=1 / 16, \mathrm{p}<.005)$, while for Group M-NDS the increase was not significant $(F=2.09, \mathrm{df}=1 / 16)$.

\section{DISCUSSION}

The significant increase for Group M-DS, analogous to the FE for instrumental measures, is interpreted as a result of frustration and provides additional support for Amsel's theory of frustrative nonreward. The fact that the no money groups, which served as controls for the OR, did not increase between the end of presentation and the beginning of nonpresentation weighs against the possibility that the increase for Group M-DS could be explained on the basis of an OR. The fact that the increase for Group M-NDS was not significant supports Longstreth's position that the presence of reward cues during nonreward facilitates the development of frustration.

A possible explanation of the increase for the combined no money group toward the end of presentation, as compared with the combined money group, might be that the no money group became annoyed with their valueless task. However, in view of the fact that the no money groups declined at the beginning of nonpresentation, it is still reasonable to interpret the increase for Group M-DS as a result of frustration.

\section{REFERENCES}

AMSEL, A. The role of frustrative nonreward in noncontinuous reward situations. Psychological Bulletin, 1958, 55, 102-119.

AMSEL, A., \& HANCOCK, W. Motivational properties of frustration: III. Relation of frustration effect to antedating goal factors. Journal of Experimental Psychology, 1957, 53, 126-131.

BROWN, J. S., \& FARBER, I. E. Emotions conceptualized as in tervening variables-with suggestions toward a theory of frustration. Psychological Bulletin, 1951, 48, 465-495.

LONGSTRETH, L. E. Frustration and secondary reinforcement concepts as applied to human instrumental conditioning and extinction. Psychological Monographs: General \& Applied, 1966, 80(11, Whole No. 619).

WINER, B. J. Statistical principles in experimental design. New York: McGraw-Hill, 1962.

\section{NOTES}

1. This study was supported in part by Research Grant No. MH-11989, from the National Institute of Mental Health.

2. Now at Manhattanville College, Purchase, N.Y. 10577 . 